\title{
Analysis on the teaching evaluation of College Physical Education under the background of new teaching idea
}

\author{
Linlin $\mathrm{Li}^{1, \mathrm{a}}$ \\ ${ }^{1}$ School of Physical Education of Sichuan Agricultural University, Ya'an, Sichuan, China \\ a245114871@qq.com
}

Keywords: colleges and universities; sports; new teaching concept; teaching evaluation.

\begin{abstract}
China's education industry, we have put forward higher requirements for physical education in Colleges and universities. PE teaching evaluation is an indispensable part in the process of physical education teaching. It can help to train students' ability to exercise, improve their physical literacy, strengthen physical exercise interest, develop good exercise habits and achieve complete physical education. The main content of the evaluation of College Physical Education Teaching in the new teaching idea is to choose the teaching goal and the teaching principle. We help students to develop physical education by setting goals and using appropriate teaching models. This process should be determined by the use of physical education teaching evaluation.
\end{abstract}

\section{Introduction}

Measures to deepen the reform of education in China to promote the reform of physical education in Colleges and universities. CPC Central Committee and State Council formulated the relevant guidelines for college sports teaching, which made it clear that universities should respect the autonomy of students and teachers teaching content [1]. So colleges and universities should attach importance to the application of teaching evaluation in college physical education. Universities can by means of diversified evaluation activities to improve students' interest in sports, and promote students in learning physical knowledge and physical exercise, so that students enter the society can quickly adapt to the social environment, eventually become talents social needs.

\section{Application status of college physical education teaching evaluation system under the new teaching idea}

The orientation of physical education teaching evaluation system is not reasonable. The main reason for carrying out the evaluation of teaching quality in the course of physical education is to inspect and supervise the teaching situation of the teachers with the aid of the teaching evaluation system. On the one hand, it can help teachers to find their own shortcomings in the teaching process. On the other hand, this initiative gives the students the opportunity to self evaluate and reflect on themselves. Teachers can through the teaching evaluation system to analyze the students' physical education learning situation, at the same time to understand the learning process of their own shortcomings [2]. But in the actual operation process of PE teaching evaluation in Colleges and universities, some teachers will be teaching evaluation as the ultimate goal. With the help of the school grade corresponding to teacher students' examination results, but no clear feedback performance information, which leads to the sports teaching process is too technical, and teaching methods to mechanization, and give the evaluation of physical education utilitarian strong. Schools fail to pass the problems in the teaching evaluation system feedback, which is contrary to the original intention and purpose of the sports teaching evaluation system, and can not play the true value of the teaching evaluation system [3]. Therefore, the application of sports teaching evaluation system can not stimulate students' interest in sports learning, also fail to cultivate students' ability of physical exercise or develop the habit of physical exercise, which is not conducive to the improvement of the quality of physical education. 
The content of the evaluation system of physical education teaching is not balanced. There is a common problem in the development of the evaluation system of PE teaching, that is, the content of the evaluation is not balanced. This major and most universities focus on technology to ignore the interests of. Because of the importance of teaching results and test results in college teaching, colleges and universities generally use the theoretical assessment, skills assessment to assess the students' learning situation. However, the evaluation of students' mental and physical training ability of students is lack, which leads to the lack of cooperative spirit, sports consciousness, sports participation enthusiasm and so on. Although the above content is relatively subtle, but it should also be used as a sports teaching content, which has a positive effect on students' enthusiasm for learning sports. By stimulating the students' interest and enthusiasm in physical training can help students to develop good exercise habits and physical consciousness. Therefore in the development of teaching evaluation should not only pay attention to the students' physical education achievement, but also should be targeted to stimulate and tap the potential of the students' physical exercise. Schools should help students to better self understanding and build up their confidence in physical exercise by meeting the appropriate needs of students. Colleges and universities should combine their own situation with the help of multi objective evaluation, qualitative analysis and quantitative analysis to improve the evaluation system of physical education teaching, and improve the evaluation system of College Physical Education teaching.

College physical education teaching evaluation and orientation is not scientific. Because of the deviation of the orientation of college sports teaching evaluation, the evaluation content setting is narrow. In the actual development of teaching evaluation in secondary schools, more emphasis on quantitative evaluation, absolute evaluation and final evaluation, while the school has not carried out qualitative evaluation, self-evaluation and process evaluation. That is to say in the development of school physical education teaching evaluation in too much emphasis on the measurable indicators, and often neglect non measurement and evaluation of the contents of this result evaluation method has one sidedness, and not effective feedback of teaching information, teaching students and teachers will not be the next stage of physical education learning to provide valuable data for [4]. Carrying out teaching evaluation is only an evaluation of students' ability of physical education. At present, the physical examination in Colleges and universities is more than the standard and method of unified formulation to assess students' sports ability. But there are great individual differences among students themselves. Some students have weak physical quality, so the evaluation of the unified standard will ignore the students' efforts. This is contrary to the idea of people-oriented teaching, and is not conducive to the all-round development of students. From the other point of view, the evaluation of physical education teaching has stronger comparability and maneuverability. It can make a quantitative evaluation according to the students' physical ability and motor skills. But in the evaluation process, it is easy to ignore the difficult content. Such as students' psychological reaction, moral character, social adaptation ability, etc.. If things go on like this, the sports teaching must be combined with the system of education and treatment skill education teaching goal divergence [5]. Although the system can be used to a certain degree of evaluation of student achievement, but it is only applicable to the assessment of the end of the final. In the daily teaching process will not be able to capture the students learning situation, but also can not improve the quality of teaching, encourage students to carry out physical exercise, improve teaching methods, etc..

College physical education teaching evaluation of the effect is not ideal. If you want to build a teaching evaluation system with vitality, scientific and reasonable, it is necessary to ensure that it is universally recognized, and can be widely used in teaching process. It is found that the result of teaching evaluation is mainly affected by the main body of evaluation. If the evaluation of the main body with diversity can be reduced by the evaluation of the main body is too single caused the difference. This can optimize the evaluation structure, and improve the credibility and effectiveness of the evaluation method [6]. However, some students have no clear understanding of the evaluation system of physical education teaching, and face the teaching evaluation attitude, these phenomena will lead to poor teaching evaluation. Students are not only the main body of the evaluation system of 
physical education, but also the experience of teaching activities. Therefore, they have the most say to the teaching evaluation system, at the same time, they also have the main significance to the development of the teaching evaluation. But the reality of teaching evaluation is part of the process of students in accordance with their own preferences or demands on Teachers' teaching ability and quality judgment, negative influence of rationality, objectivity and validity of the teaching evaluation, also led to a few teachers for teaching evaluation is relatively low. Some teachers in order to improve the evaluation of teaching in the teaching process is too to meet the needs of students, and even the overall quality of teaching [7]. Because the school to carry out the teaching evaluation results are not published, which led to the students' teaching evaluation work, and think that they do not seriously affect the evaluation will not. Therefore, the evaluation system can not be feedback on the actual situation, which led to the evaluation of teaching effect is not ideal.

\section{The method of evaluation of physical education in Colleges and Universities under the new teaching idea}

Ensure students' all-round development. Under the guidance of the new teaching idea, the university should strengthen the cultivation of students' psychological quality, the victory quality and the ability of social adaptation. Therefore, the university should be in the teaching content to join the comprehensive quality education, which aims to improve students' behavior habits, emotional and cognitive level, etc.. Let the students in the activities clearly reflect their own sports habits, health awareness and knowledge level. Schools can be based on the problems of students to carry out physical education, in order to improve their comprehensive ability to ensure that students personalized development, and better and faster to adapt to social [8].

Determine the main status of students. In the course of physical education, students should be embodied in the subject position and role of the main body. The school should enhance the students' learning interest and confidence, strengthen the initiative and enthusiasm of the physical exercise, and improve the ability of physical exercise and sports skills under the guidance of the physical education teacher. Therefore, teachers should take the students as the main body in the teaching design and teaching practice, and pay attention to the cultivation of students' abilities, and expand their employment opportunities.

Cultivating students' Sports Consciousness. Under the guidance of the new teaching concept, the university should rebuild the evaluation system of physical education teaching, in order to strengthen the students' consciousness of physical exercise and the consciousness of physical exercise. The ultimate goal of the school through the sports teaching, and increase teaching in the course of interest, health and entertainment to help stimulate students' love of sports, help students consciously establish exercise consciousness in the process of actively participate in sports activities, and gradually develop the habit of physical exercise, achieve the final evaluation value.

\section{The tendency of College PE teaching evaluation under the new teaching idea}

The development of college physical education teaching should be based on the new teaching idea to develop teaching objectives, and according to the teaching objectives and the quality of education in a comprehensive, basic, individual, the subjectivity of the development of a new evaluation system of physical education. Schools should optimize the content and related indicators of evaluation, and to ensure that the teaching evaluation to the system, the scientific direction of development. The university should change the teaching evaluation concept in time, and strengthen the teaching process, namely, the evaluation of teaching effect, so that it is converted from the former single teaching evaluation to multiple. Because the students are the main body of the sports teaching activities, it is also the main body of sports teaching evaluation. Therefore, we should pay more attention to the role of students in teaching, which can help teachers to understand the actual teaching situation and teaching quality. Colleges and universities can carry out a number of teaching evaluation system based on the actual situation of the school teachers, students and peer assessment, which can promote the integrity and the main body of the evaluation system of physical education teaching. We should 
help students to exercise the cognition in the process of teaching, and help students develop the habit of exercise, which can help students to develop a good habit of exercise or exercise autonomy in a certain extent. Therefore, in the development of physical education in Colleges and universities should be the combination of physical exercise and daily life, and to strengthen the degree of attention of the students. At the same time, according to the differences of students' physical quality, a number of sports teaching activities are carried out. Such as badminton, basketball, useful, national dance, Latin dance, gymnastics and other elective courses, which is conducive to improve student interest in sports learning.

\section{Conclusions}

At present, there are some deficiencies in the evaluation system of physical education in Colleges and universities, which has an impact on the role of teaching evaluation to a certain extent. Therefore, we should reform the teaching evaluation system in a timely manner. Schools should be improved for the existing problems, and improve the evaluation index and content, and fully mobilize the students' subjective initiative of physical exercise.

\section{Acknowledgement}

Funding project: this paper is funded by undergraduate thesis incubation programme of Sichuan Agricultural University.

\section{References}

[1] Zhang Zhishang. Journal of the university sports teaching evaluation of the status quo and development trend of $[\mathrm{J}]$. of Chifeng University (NATURAL SCIENCE EDITION), 2015,05:210-211.

[2] Yin Zhenghui. College sports on the teaching reform of the [J]. Agricultural Higher Education under the concept of lifelong sports, 2015,04:67-69.

[3] Fan Jianwei. Colleges and universities sports teaching evaluation of [J]., 2015,07:122-124. (martial arts fighting Science)

[4] Wang Lei. The evaluation system of classroom teaching evaluation of physical education teachers in Colleges and universities [J]. education and career, 2013,36:185-187.

[5] Xi Yu. Research on the present situation of the implementation of the evaluation of College Physical Education Teaching in the new teaching concept [J]. education modernization, 2016,05:186-192.

[6] Wang Xihong. Ideas and Countermeasures of innovation of the evaluation system of physical education in Colleges and universities [J]. Henan science and technology, 2015,21:261.

[7] Shen Jun, Li Yonggang. Study on the construction of evaluation system of College Physical Education Teaching in the background of the new teaching concept [J]. sports, 2016,05:72-73.

[8] Xia Junmei, Yu Ling, Hu Jianhong, et al. The "people-oriented" concept of innovation in college physical education achievement assessment model [J]. innovation and entrepreneurship education, 2016,03:122-127. 